\title{
Older People Receiving Public Long-Term Care in Relation to Consumption of Medical Health Care and Informal Care
}

\author{
Staffan Karlsson ${ }^{*, 1}$, Anna-Karin Edberg ${ }^{1,2}$, Albert Westergren ${ }^{3}$ and Ingalill Rahm Hallberg ${ }^{1,2}$ \\ ${ }^{I}$ Department of Health Sciences, Faculty of Medicine, Lund University, P.O. Box 157, SE-221 00 Lund, Sweden \\ ${ }^{2}$ The Vårdal Institute. The Swedish Institute for Health Science, Lund University, P.O. Box 187, SE-221 00 Lund, \\ Sweden \\ ${ }^{3}$ Research and Development Unit, Central Hospital, SE-291 85 Kristianstad, Sweden
}

\begin{abstract}
The aim of the study was to investigate medical health care and informal care consumption among older people receiving public long-term care, and factors associated with medical health care consumption. 1958 persons aged 65 years and over were included. Data were collected from two registers, including demography, functional ability and received long-term, informal and medical health care. $35 \%$ of those at home were admitted to hospital and $76 \%$ had contact with outpatient care by physician compared to $26 \%$ and $87 \%$ respectively of those in special accommodation. Living in special accommodation was associated with more contacts with primary health care and fewer contacts with specialist care other than psychiatric care. Informal care was associated with more contacts with primary health care, specialist care, admissions to and days in hospital. More elderly people being cared for at home may mean more hospital and outpatient care consumption.
\end{abstract}

Keywords: Aged 80 and over, utilization, public long-term care, informal caregiver, medical care.

\section{INTRODUCTION}

The growing elderly population, consisting of more people who have to live with a number of diseases and various forms of functional dependence, entails a complex life situation for the individual. It is also a challenge for public medical health and long-term care and service, as well as for families [1]. As in many other countries, the municipalities and the county councils are the two main providers of health care and social services in Sweden, which makes it difficult to obtain an overall view of care consumption in individual cases. There may be a risk that older people get stuck in the middle or that authority will try to pass the responsibility on to another provider. To our knowledge, no studies have integrated data from both providers, nor has informal care been taken into account, when investigating medical health care consumption. Such knowledge is needed to further develop medical health and long-term care and to understand how the public system works in relation to individual cases.

Knowledge of how medical health care and public longterm care is distributed to very old people is needed to adapt the system to those with complex needs and illnesses. The growing number of older people increases the demands on municipalities and medical health care, due to that age related changes may have a significant impact on medical care consumption. Findings by McGrail et al. [2] in Canada indicated that consumption of emergency health care increased with age. It may well be that the pattern of health care consumption differs during the period from 65 years of age to

*Address correspondence to this author at the Department of Health Sciences, Faculty of Medicine, Lund University, P.O. Box 157, SE-221 00 Lund, Sweden; Tel: +46 4622218 32; Fax: +46 4622218 46;

E-mail: staffan.karlsson@med.lu.se death. A study including persons aged $75+(n=278$, USA $)$ investigated the total cost of health care, including hospital care, outpatient visits and durable medical equipment. The oldest age group $(90+)$ received less extensive treatment than the younger age group (75-79 years) [3]. Another study in the USA ( $n=53$ 195) showed that the medical expenditure on older people in the last year of life was lower among people aged 85 and over compared to those between 65 and 74 [4]. The explanation for this may be that the oldest people were not prioritized or that they received care elsewhere, either at home or in special accommodation. Thus, there is a need for more knowledge of how the care consumption is distributed among different agencies and about the relationship between care at home or in special accommodation and medical care consumption. The trend with regard to long term care is that older people should remain at home for as long as possible [5]. Those living in special accommodation (nursing home) have been found to be older, more functionally dependent and to have a higher number of health complaints than those living at home [6]. Also, a study in Israel $(n=1820)$ showed that older people who were dependent in three to five ADL activities were more likely to live in special accommodation than at home [7]. In Sweden, the number of older people receiving care at home increased by $10 \%$, while those receiving care in special accommodation decreased by $11 \%$ between the years 2000 and 2004 [8]. Thus, those cared for at home seem to be in an increasingly frail condition. This may well mean that the need for more skilled medical attention is needed with implications for the providers of medical health care in that hospital care and the consumption of specialist outpatient care will increase. Knowledge of factors determining the distribution between care at home $v s$ care in special accommodation is sparse. Also, due to the lack of data on individuals receiving public long-term care and service, it has not been possible to ascertain whether an increased de- 
mand on hospital and primary health care is related to how long-term care is provided. There is currently a lack of knowledge of the total care provided to older people.

In addition to the public authorities, informal carers play an important role in providing care for older people. This may have an impact on health care consumption, depending for instance on how well prepared they are to take on the responsibility. A comparative study $(n=1378$ and $n=4583$, respectively) between Sweden and the United States showed that $23 \%$ and $27 \%$, respectively, of people aged $75+$ only received informal care. In the same sample, $19 \%$ of the Swedish subjects received a combination of public and informal care while the corresponding figure was $17 \%$ in the United States. The pooled sample revealed that IADL needs were associated with informal care only, while PADL needs involved a combination of informal and public care [9]. Thus, public care seems to interact with informal care when older people require more extensive care and service. The extensive involvement of informal carers illuminated by the results of two Swedish studies by Hellström and co-workers $(n=448$ and $n=1247)$ showed that family members were the main providers of care to dependent people aged $75+$ who lived at home $[10,6]$. The more recent of the aforementioned two studies [6] showed that $84 \%$ of the older people received informal care compared to $79 \%$ in the earlier study. Thus, family members seem to provide the bulk of the care for older people, also in countries supposed to have a publicly financed welfare model. In 1994, informal caregivers provided $60 \%$ of the care to older people living at home in Sweden, while in 2000, the corresponding figure was $70 \%$. [11]. Informal care thus should be taken into consideration when investigating the health care consumption of older people. Studies investigating the relationship between public longterm care, medical health care and informal care may be helpful in providing knowledge that can guide the improvement of the public system, as well as the collaboration with informal caregivers.

\section{AIM}

The aim of the study was to investigate older people receiving public long-term care and services either at home or in special accommodation in relation to medical health care and informal care consumption, and to investigate factors associated with medical health care consumption.

\section{METHODS}

\section{Context}

In Sweden, a majority (93\%) of people aged $65+$ live at home. Very few live with their adult children and about $40 \%$ live alone. Some 15\% (about 240000 individuals) of people over 65 years of age receive public long-term care and services, $8 \%$ at home and $7 \%$ in special accommodation [8]. Special accommodation is defined as a municipal institution providing 24-hour care, including care from a registered nurse and resemblance what internationally is called nursing homes [12]. The Social Services Act regulates municipal care and services for older people, including home care and services and care in special accommodation [13]. Care and service is preceded by an assessment of need and a decision about how much and how to provide care and service. Health care and rehabilitation provided by municipalities and county councils is regulated by the Health and Medical Services Act [14]. The municipalities are responsible for providing long-term care and service, including home care and service, home nursing care and rehabilitation, while the county council is responsible for medical health care, hospital and outpatient care. In some parts of the country, the county council is responsible for home nursing care and rehabilitation instead of the municipalities [15]. In the county of Scania, where this study was performed, the municipalities are responsible for home nursing care. In Sweden, care and services have been a primarily public responsibility for many years. The public budget at central and local (government and municipal) levels cover the cost of public longterm care. Each individual municipality allocates long-term care and services to older people on the basis of frameworks such as laws and current financial and policy documents [15].

\section{Sample}

A total of 1958 people, all of whom received long-term care and service from the municipality, either at home or in special accommodation, were included in this study. The study design was cross-sectional and data was collected during 2001. All persons $(65+)$ receiving care and service in four municipalities, who had been granted public care and services at home, or care in special accommodation, or who received at least four home nursing or rehabilitation visits per month, were regarded eligible for inclusion in the study. Persons with only safety alarms, meals on wheels or transport services were excluded. Two municipalities were small towns including rural areas, one was a medium-sized city including rural areas and one municipality was rural only.

\section{Measurement}

For assessment, a questionnaire built up around validated measures was developed covering demographic data, functional ability, health complaints, adaptation and standard of accommodation, as well as public and informal care. Demographic data included age, gender, marital status and type of accommodation. The questionnaire was based on existing literature and on consultations with an expert group, including researchers in geriatrics, gerontology, nursing science and social science [16]. Physical functional ability for PADL was measured by the Katz ADL index and consisted of: hygiene, dressing and undressing, ability to go to the bathroom, mobility, ability to control bowel and bladder, and food intake [17]. Variables for IADL included ability to clean, buy food, manage transportation and cook [18]. One variable related to doing laundry was added, after consultation with the expert group. Each variable had the following response alternatives: independent, partly dependent or dependent. The Berger scale was used to measure cognitive ability. Cognitive dependency was assessed by seven predefined alternatives, ranging from no cognitive dependency to bedridden and mutistic [19].

In the section covering public care and services, decisions related to the Social Services Act [13] and the Health and Medical Services Act [14] were recorded. The Social Services Act regulates care and services at home, including day, evening and night time care as well as care in special 
accommodation, and the response alternatives were: no, yes and don't know. The questions concerning care and service at home were specified with regard to care in the areas of IADL and PADL, and by hours per week. Home nursing care, as regulated by the Health and Medical Services Act, included day, evening and night time care, and response alternatives were: no, yes and don't know in each section. The frequency of home nursing care was specified by visits per month from a registered nurse, assistant nurse or other staff, while the extent of home nursing care was calculated by hours per month with respect to all staff. The questionnaire also included items about informal care, which were divided into help with IADL and help with PADL and who provided it: spouse, child, brother or sister, grandchild, other relative, neighbour/friend, privately financed care or care from associations/voluntary organizations. The response alternatives for each helper were: not applicable, no care, care less than once a week, more than once a week, daily care and do not know [16].

Data concerning medical health care provided by the county council were collected from the county council administrative register (PASiS) [20, 21], which contains information on hospital care and outpatient care for each individual in the county and is recorded by the staff. This is a routine procedure and the data forms the basis for subsidies to each unit/department. The data used in this study comprised number of admissions and days in hospital. The outpatient care data concerned contacts with primary health care, psychiatric care and specialist care other than psychiatric care. Contact with outpatient care included face-to-face as well as telephone contact with a physician.

\section{Procedure}

The data collection procedures in the municipalities were first tested in a pilot study that resulted in minor adjustments [22]. The staff received information and instructions before the study commenced. The subjects gave informed consent before the start of data collection. In cases where the individual was incapable of giving his/her consent, the next of kin gave it. In the municipalities, the registered nurses represented care and service in special accommodation and home nursing care, home help officers represented home help, and occupational therapists and physiotherapists represented rehabilitation. The instruction to the staff was to collect current data about the older people receiving care and service. In cases with a recent assessment or frequent contact data were collected through personal information and documentation, in other cases a new assessment was made. The data from the municipalities was individually linked, through a 10 digit personal number, to the PASiS data about hospital and outpatient care during 2001. The Ethics Committee of the Medical Faculty, Lund University, approved the study (LU 650-00 and LU 744-00).

\section{Analysis}

Non-parametric statistics was used for comparison between age groups and accommodation (at home or in special accommodation). For categorical variables, the KruskalWallis test was used to compare three independent groups and the Mann-Whitney U-test between two independent groups. The chi-square test (Fisher's exact test when appli- cable) was applied to the analysis of differences between two and three independent groups measured on an ordinal scale. A p-value below 0.05 was considered significant. When multiple comparisons were made, a reduced p-value of $<0.017$ was used to avoid mass significance [23]. The index for ADL had been calculated by means of factor analysis, which resulted in three components: Personal Activities of Daily Living (SNAC-PADL index), Instrumental ADL (SNACIADL index) and Psychosocial Needs (SNAC-Psychosocial index) [24]. The SNAC-PADL included transfer, going to the bathroom, faecal incontinence, urinary incontinence, mobility, dressing, eating and cognitive ability (Cronbach's alpha 0.91). The SNAC-IADL included washing, shopping, cooking, bathing, transportation, cleaning and going outdoors (Cronbach's alpha 0.86). The SNAC-Psychosocial Needs included anxiety, depressed mood, difficult behavior, need for supervision and special care needs (Cronbach's alpha 0.72). Multiple linear regression analyses were performed with medical health care consumption regarding outpatient care by physician and hospital care as the dependent variables. The forward method was employed for the independent variables; gender, type of accommodation, informal care, the SNAC-IADL and the SNAC-Psychosocial indexes. Age and the SNAC-PADL index were additional independent variables which were held constant, by means of the enter method. The SPSS version 11.5 was used for all statistical analyses.

\section{Dropout Analysis}

The exact number of people receiving municipal care and services is not available, as there are only official statistics on group level. Based on Swedish group statistics [25], it was estimated that a total of 4288 older people received public long-term care in the municipalities concerned. Calculations on this estimate indicated that $1958(46 \%)$ had agreed to participate, thus about $1858(43 \%)$ had not been invited to participate whilst $472(11 \%)$ declined participation. The mean age of those who declined was 85 (SD 7.0) with $12 \%$ in the 65-74 age group, $36 \%$ in the $75-84$ age group and $52 \%$ aged $85+$. Among those who declined participation, $71 \%$ were women.

A special file including all care and service recipients in accordance with the inclusion criteria of this study was linked to the county council administrative register (PASiS). This allowed for comparisons of the medical health care received from the county council between the study group and those who had declined or had not been invited to participate. No differences between the study group and the dropout group were found concerning contact with physician in primary health care or in specialist care other than psychiatry in outpatient care, except when it came to psychiatric care. The study group had more contact with psychiatric outpatient care (median=1, range $1-8$ ) compared to the dropouts (median $=1$, range $1-6)(\mathrm{p}=0.031)$. The number of days in hospital and days per hospital stay was lower among those in the study group (median=10, range $1-100$, and median $=6$, range $1-57$, respectively) than those in the dropout group (median $=13$, range $1-172$, and median $=7$, range $1-165$, respectively) $(p<0.001)$. The effect from internal dropout (i.e. no response to an individual item) was analyzed in terms of the SNAC-IADL, SNAC-PADL and SNAC-Psychosocial 
indexes. When those with complete indexes were compared with the missing data it was found that the missing data mainly derived from those at home regarding SNAC- PADL and Psychosocial index ( $\mathrm{p}<0.001$ and 0.004 respectively), while missing data regarding SNAC-IADL index derived from those in special accommodation $(p<0.001)$.

\section{RESULTS}

$49 \%$ of the care recipients had care in special accommodation. Their mean age was 85 year compared to a mean age of 82 for those receiving care and service at home. $71 \%$ of those in special accommodation were women compared to
$66 \%$ at home, and $49 \%$ had moderate/severe cognitive dependency compared to $13 \%$ among those receiving care and service at home. Among those in special accommodation, $91 \%$ were greatly/totally dependent in IADL compared to $43 \%$ among those at home, $30 \%$ were greatly/totally dependent in PADL compared to $6 \%$ among those receiving care and service at home, and $13 \%$ had extensive/very extensive psychosocial needs compared to $7 \%$ at home. Of those living at home who had both formal and informal care, $48 \%$ were greatly/totally dependent in IADL compared to $33 \%$ among persons living at home who received formal care only (Table 1).

Table 1. Demographic Data and Functional Ability, Comparisons Between Type of Accommodation and Public Care Only and Both Public and Informal Care at Home

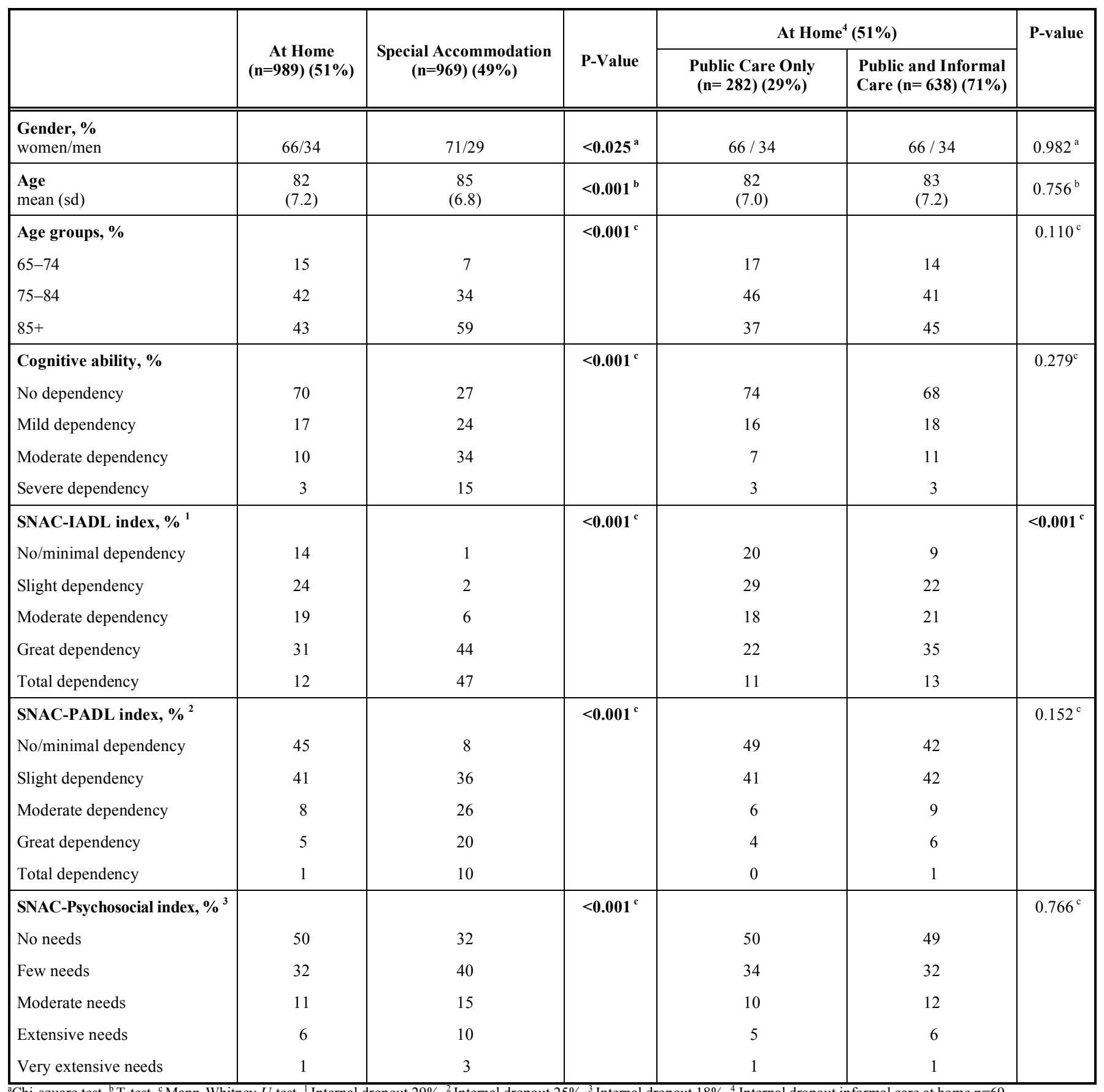

${ }^{\mathrm{a}}$ Chi-square test, ${ }^{\mathrm{b}} \mathrm{T}$-test, ${ }^{\mathrm{C}}$ Mann-Whitney $U$-test, ${ }^{1}$ Internal dropout $29 \%,{ }^{2}$ Internal dropout $25 \%,{ }^{3}$ Internal dropout $18 \%,{ }^{4}$ Internal dropout informal care at home $\mathrm{n}=69$. 


\section{Living at Home with Public Care and Service}

Among those living at home who received public longterm care $(51 \%), 76 \%$ received care and services, $62 \%$ received home nursing care and $64 \%$ received informal care in addition, distributed as help with IADL in $64 \%$ and with PADL in $48 \%$. Help with PADL was more frequent than IADL help. Home nursing care visits was provided to $44 \%$ by registered nurse accounted for 7.2 visits per month in mean and $37 \%$ by assistant nurse with the corresponding figure 35.6 visits per month. Informal care in addition to public care, $99 \%$ was distributed as help with IADL and $36 \%$ as help with PADL. Help with IADL was provided by children in $65 \%$, while help with PADL was provided by a spouse in $20 \%$. Spouse gave the help daily and children at least once a week (Table 2).

\section{Medical Health Care}

In the course of twelve months, 598 persons (31\%) from the study group were admitted to hospital. Those who received hospital care had in mean 1 admission; (range 1-12) lasting for in mean 6 days; (range 1-57). Of those living at home with public care and service, $35 \%$ were admitted to hospital during the year of the study compared to $26 \%$ of those living in special accommodation. Hospital care was significantly more common among persons receiving both public and informal care at home (39\%) with regard to number of admissions and days in hospital, compared to those living in special accommodation. Outpatient health care provided by primary health care (PHC) physicians was received by $73 \%$, specialist care other than psychiatric care by $58 \%$ and psychiatric outpatient care by $2 \%$. Of those receiving outpatient care, the most frequent contact was with specialist care other than psychiatry compared to primary health care and psychiatric care. Among persons in special accommodation, $81 \%$ had contact with primary health care physicians compared to $67 \%$ of those living at home with public care and service. Specialist outpatient contact with a physician was in median 3 in those receiving public care only at home and in median 4 among those receiving both public and informal care at home, compared to in median 2 for those living in special accommodation (Table 3 ).

Admission to hospital was associated with informal care. Having very extensive psychosocial needs and low level of dependency in PADL was associated with more days in hospital, while male gender and total dependency in PADL was

Table 2. Care and Service Provided by the Municipality and Informal Caregivers at Home

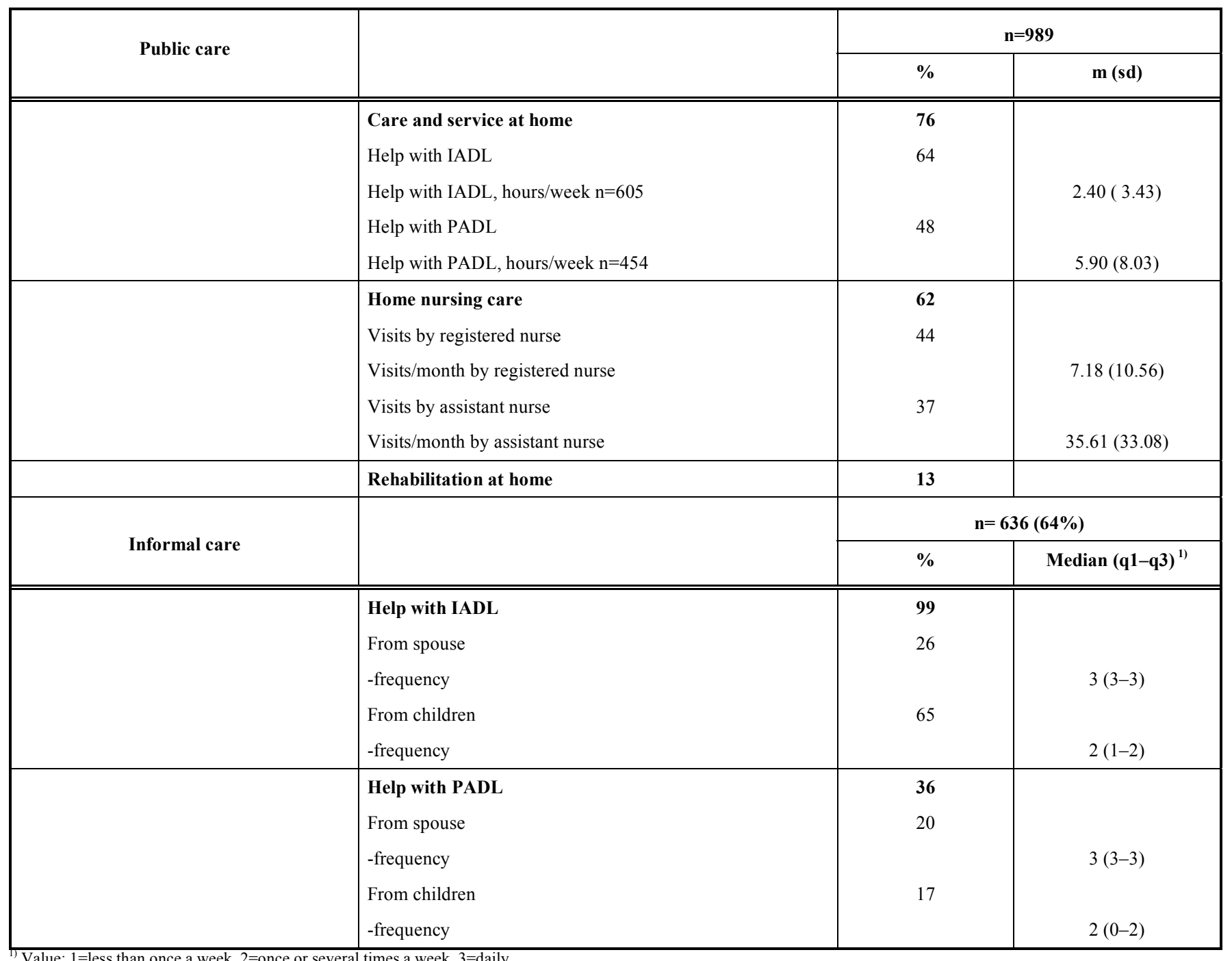


Table 3. Care Provided by the County Council in Relation to Type of Accommodation

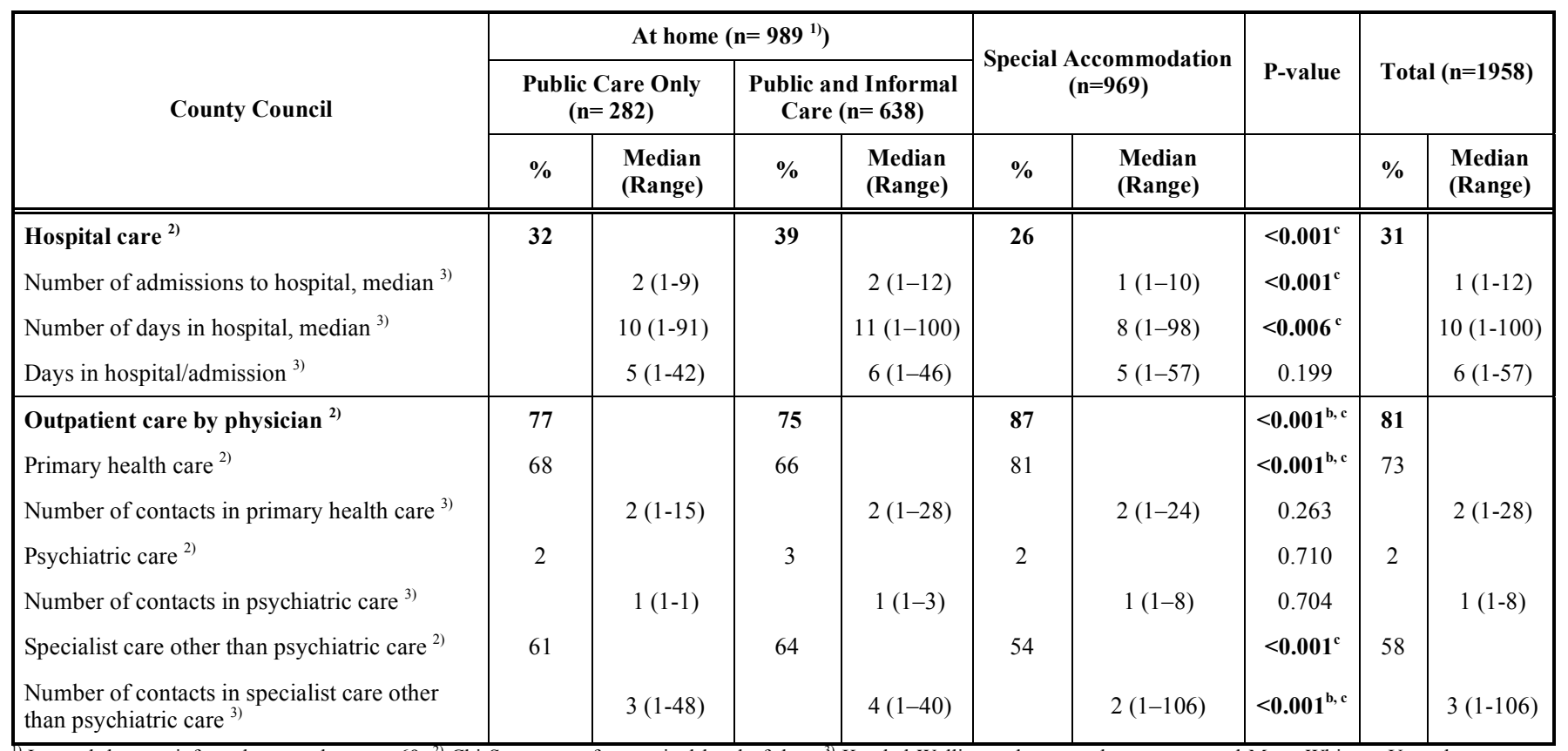

Internal dropout informal care at home $\mathrm{n}=69,{ }^{2)}$ Chi-Square test for nominal level of data, ${ }^{3)}$ Kruskal-Wallis test between three groups and Mann-Whitney $U$-test between two groups for interval level of data. Reduced p-value $<0.017$ used between two groups. apublic care only at home differs from a combination of public and informal care at home, public care only at home differs from special accommodation, ${ }^{\mathrm{c}}$ combination of public and informal care at home differs from special accommodation.

associated with fewer days in hospital. Contact with primary health care was associated with living in special accommodation, informal care, while total dependency in PADL was associated with fewer contacts with primary health care. Contact with psychiatric care was explained by psychosocial needs; moderate, great and very great. Contact with specialist care other than psychiatric care was associated with informal care, while living in special accommodation and great or total dependency in PADL was associated with fewer contacts with specialist care other than psychiatric care (Table 4).

\section{DISCUSSION}

The number of subjects included in the study was estimated to be low $(46 \%)$, which could pose a threat to external validity, affecting the extent to which the results can be generalized [26]. The issue, however, depends more on whether the dropout is systematic than on its size. The distribution of age and gender among the dropouts resembled those who participated, although a higher proportion of the latter lived in special accommodation $(\mathrm{p}<0.001)$, which indicates that more people with reduced functional ability were included. In this study, $49 \%$ lived in special accommodation while, in Sweden as a whole in $2005,40 \%$ of those receiving municipal care and service lived in special accommodation [27]. About $11 \%$ declined to participate in the study, while approximately $43 \%$ had not been invited to participate. The representativeness of the sample thus can be questioned. The internal dropout in the SNAC-indexes was mainly among those in special accommodation. The explanation for that may be that help with IADL is included in the care and social services provided in special accommodation. Thus, that variable may not be valid for those living in special accommodation. Dropout associated with PADL and psychosocial dependency was higher among those living at home and could be due to insufficient knowledge among the staff concerning these needs. However, the sample can be regarded as rather valid, due to the large number of individuals and due to that the data concerned older people's care and service, medical health care as well as informal care.

The study was based on data collected by staff, which may be a threat to the internal validity [26]. The interrater reliability of the questionnaire, for example, was not tested as a whole, although it included reliable and valid instruments such as the Berger scale [19], the Katz ADL index [17] and the Hulter-Åsberg index for IADL [18]. The SNAC index developed for IADL and PADL has shown high correlation with the Katz ADL index for PADL and the HulterÅsberg index for IADL (Cronbachs's alpha 0.91 and 0.86 respectively) [24]. Furthermore, the SNAC index had a stronger relation to the care and services provided than either the Katz ADL index or the Hulter-Âsberg IADL index, which indicates that the summarized SNAC index better explains care needs than separate use of the scales. No control for validity and reliability was performed on the county council (PASiS) register. The PASiS register has, however, been in operation since the early 1990s and is a wellestablished routine among the staff as well as connected to payment in the county council. These circumstances most likely increased the reliability of the data collected.

The trend towards more elderly people being cared for at home may mean more hospital and outpatient care by physicians, thus transferring responsibility to the medical health care system provided by the county councils. People living at home had more frequent hospital admissions than those living in special accommodation; $35 \%$ of those living at home were admitted to hospital compared to $26 \%$ of those living in special accommodation $(\mathrm{p}<0.001)$. Care and service at home 
Table 4. Variables Associated with County Council Health Care Consumption

\begin{tabular}{|c|c|c|c|c|c|c|}
\hline Hospital Care & Independent Variables & B & Adjusted $\mathbf{R}^{2}$ & \multicolumn{2}{|c|}{ 95\% Confidence Interval } & P-value \\
\hline \multirow[t]{7}{*}{ Admissions to hospital } & Age & -0.025 & .023 & -0.043 & -0.006 & $<0.009$ \\
\hline & Male gender & -0.198 & & -0.467 & 0.070 & 0.147 \\
\hline & Having informal care in addition & 0.265 & & 0.007 & 0.524 & $<0.044$ \\
\hline & SNAC-PADL index -slight dependency & -0.021 & & -0.284 & 0.326 & 0.893 \\
\hline & SNAC-PADL index -moderate dependency & -0.215 & & -0.585 & 0.151 & 0.250 \\
\hline & SNAC-PADL index - great dependency & -0.242 & & -0.719 & 0.235 & 0.319 \\
\hline & SNAC-PADL index - total dependency & -0.594 & & -1.677 & 0.502 & 0.284 \\
\hline \multirow[t]{8}{*}{ Days in hospital } & Age & -0.092 & .033 & -0.173 & -0.012 & $<0.025$ \\
\hline & Male gender & -1.218 & & -2.437 & 0.000 & $<0.050$ \\
\hline & Having informal care in addition & 1.573 & & 0.366 & 2.780 & $<0.011$ \\
\hline & SNAC-PADL index -slight dependency & 2.754 & & 1.245 & 4.262 & $<0.001$ \\
\hline & SNAC-PADL index -moderate dependency & 0.585 & & -1.078 & 2.248 & 0.491 \\
\hline & SNAC-PADL index - great dependency & -1.406 & & -3.287 & 0.475 & 0.143 \\
\hline & SNAC-PADL index - total dependency & -3.712 & & -6.333 & -1.092 & $<0.006$ \\
\hline & SNAC-Psychosocial index - very extensive needs & 3.629 & & 1.361 & 5.897 & $<0.002$ \\
\hline \multicolumn{7}{|l|}{ Outpatient care by physician } \\
\hline \multirow{8}{*}{$\begin{array}{l}\text { Contacts with primary health } \\
\text { care }\end{array}$} & Age & -0.036 & .013 & -0.058 & -0.015 & $<\mathbf{0 . 0 0 1}$ \\
\hline & Male gender & -0.044 & & -0.323 & 0.314 & 0.978 \\
\hline & Living in special accommodation & 0.643 & & 0.251 & 1.035 & $<0.001$ \\
\hline & Having informal care in addition & 0.413 & & 0.043 & 0.783 & $<\mathbf{0 . 0 2 9}$ \\
\hline & SNAC-PADL index -slight dependency & -0.141 & & -0.505 & 0.223 & 0.448 \\
\hline & SNAC-PADL index -moderate dependency & -0.352 & & -0.817 & 0.112 & 0.137 \\
\hline & SNAC-PADL index - great dependency & -0.271 & & -0.807 & 0.264 & 0.321 \\
\hline & SNAC-PADL index - total dependency & -0.863 & & -1.607 & -0.120 & $<\mathbf{0 . 0 2 3}$ \\
\hline \multirow[t]{9}{*}{ Contacts with psychiatry } & Age & -0.002 & .037 & -0.004 & 0.000 & $<0.016$ \\
\hline & Male gender & 0.008 & & -0.020 & 0.036 & 0.571 \\
\hline & SNAC-PADL index -slight dependency & 0.005 & & -0.026 & 0.036 & 0.757 \\
\hline & SNAC-PADL index -moderate dependency & 0.026 & & -0.014 & 0.066 & 0.202 \\
\hline & SNAC-PADL index - great dependency & -0.013 & & -0.058 & 0.033 & 0.584 \\
\hline & SNAC-PADL index - total dependency & -0.042 & & -0.105 & 0.021 & 0.192 \\
\hline & SNAC-Psychosocial index - moderate needs & 0.061 & & 0.020 & 0.103 & $<0.004$ \\
\hline & SNAC-Psychosocial index - extensive needs & 0.085 & & 0.032 & 0.138 & $<0.002$ \\
\hline & SNAC-Psychosocial index - very extensive needs & 0.363 & & 0.266 & 0.460 & $<0.001$ \\
\hline \multirow{8}{*}{$\begin{array}{c}\text { Contacts with specialist care } \\
\text { other than psychiatry }\end{array}$} & Age & -0.089 & .059 & -0.119 & -0.060 & $<0.001$ \\
\hline & Male gender & -0.351 & & -0.801 & 0.099 & 0.126 \\
\hline & Living in special accommodation & -0.722 & & -1.277 & -0.166 & $<0.011$ \\
\hline & Having informal care in addition & 0.787 & & 0.269 & 1.305 & $<\mathbf{0 . 0 0 3}$ \\
\hline & SNAC-PADL index -slight dependency & -0.004 & & -0.510 & -0.503 & 0.988 \\
\hline & SNAC-PADL index -moderate dependency & 0.337 & & -0.342 & 1.017 & 0.330 \\
\hline & SNAC-PADL index - great dependency & -0.783 & & -1.544 & -0.022 & $<0.044$ \\
\hline & SNAC-PADL index - total dependency & -1.665 & & -2.723 & -0.607 & $<0.002$ \\
\hline
\end{tabular}


as compared with care in special accommodation was also associated with less contact with primary health care and more contact with specialist outpatient care (Table 4). One reason for that may be that hospitals are reachable around the clock, while primary health care may be less available in an emergence situation. It could also be that older persons living at home decide for themselves to a higher degree. The current policy in Sweden, as in other countries, is that long term care and service for older people should preferably be provided at home, which as indicated by the findings increase the challenge for the medical health care. The range of hospital admissions were large, ranging from 1 to 12 hospital admissions per person during one year, and the admission could in total mean up to 100 days spent in hospital during one year (Table 3). The higher medical health care consumption of those living at home highlights a need for more accessible medical health care at primary level for those living at home. Also, the ability of the staff providing home care to fulfil the older people's needs may be a problem. In this study those receiving care at home had less visits per month by registered nurse ( 7 visits in mean) and more visits by assistant nurse (36 visits in mean). The fact that home nursing care is provided by less skilled staff may hinder early detection of emerging health problems. More people cared for at home may result in older people being more frequently admitted to hospital, resulting in higher costs in another organization. Higher competence with registered nurses more frequently close to older people receiving care may make it possible to solve health problems at home as an alternative to hospital care.

The findings about medical health care consumption can also be interpreted in another way, namely that persons living in special accommodation are at risk of being marginalized, since they receive less specialized medical health care than those living at home. Those living in special accommodation were significantly older, more psychosocially and cognitively dependent in IADL and PADL than those living at home $(\mathrm{p}<0.001)$ (Table 1). This indicates that they may have had more severe health problems than those living at home. The regression analysis revealed that persons who were totally dependent in PADL had fewer contacts with outpatient specialist care. Previous studies have shown decreased consumption of medical health care in the older age groups $[2,4]$, while nursing and social care increased with age [3]. The fewer days in hospital among those in special accommodation may mean that the responsibility for finalizing the treatment was transferred to the staff in special accommodation in collaboration with primary health care. This study showed that fewer days in hospital were associated with care and service in special accommodation, despite that it means medical care at a lower level. In the Swedish context, all older persons living in special accommodation should have an assigned primary health care physician (general practitioner). The present study showed that about $80 \%$ living in special accommodation had contact with a primary health care physician during the year of the study ( 2 contacts in median, range 1-24). It may indicate that persons in special accommodation may not be monitored sufficiently from a medical perspective. Perhaps one expect that $100 \%$ in special accommodation should have had at least one contact with a primary health care physician during one year. An alternative interpretation may be that registered nurses pro- vide the medical health care needed after contact with the physician. However, their skills are not on the same level as those specialized in, for instance, geriatrics. A previous study $(n=2080)$ showed that a higher distribution of nurses and physicians in special accommodation meant a lower distribution of specialist care for the residents [28]. Those living in special accommodation had more severe health problems and were more physically, mentally and cognitively dependent than those living at home. Despite this, they received less medical health care than those living at home. Additional factors that influence these differences remain to be explained.

Although Sweden is supposed to have a public care and service system, the family plays an important role in caring for elderly people. Of those receiving care and service at home $64 \%$ also received informal care. Among those who received informal care, children were the most common helpers with IADL (65\%) and spouses with PADL (20\%). These results are in line with previous studies on informal care at home $[6,10]$. Our results showed that older people receiving both informal and formal care were significantly more dependent in IADL $(p<0.001)$ than those receiving formal care only. The same pattern has been reported from a previous study [6]. Thus, those receiving informal care in addition to public care are frailer and need more care and service than those remaining at home with public care and service only. The perhaps most interesting finding was that informal care may also have an impact on the medical health care. This study showed that receiving informal care in addition was associated with more contact with primary and specialist care, more hospital admissions and more days in hospital. This may indicate that the informal carer feels insecure in providing sufficient care or is more prone to turn to the hospital when problems occur. More contacts by registered nurses for those cared for at home may be a useful preventive intervention to support the family as well as the person receiving care. As the pressure on the informal caregivers increases, the health care and social services perhaps need to develop a more structured way of supporting the informal caregiver and sharing the knowledge needed to provide care. Extensive informal care calls for planned support for family caregivers and effective collaboration between public and informal care providers.

\section{CONCLUSIONS}

Housing seems to divide the distribution of care and service, and medical health care, in different directions. Receiving care and service at home was determined by less dependency in ADL and impaired cognitive ability, and access to informal care. This may cause pressure on informal caregivers, and calls for more collaboration and support from the professional health care providers. The high consumption of hospital care among those receiving care and service at home indicates an increased need for preventive interventions, but also improved access to medical competence at home. A more frequent involvement of registered nurses in those receiving care at home may be an appropriate approach corresponding to the requirements. The lower degree of hospital care among those in special accommodation may indicate that special accommodation compensates for hospital care, despite the uncertain medical competence. 


\section{ACKNOWLEDGEMENTS}

The Swedish National study on Aging and Care, SNAC, (WwW.snac.org) is financially supported by Ministry of Health and Social Affairs, and participating county councils, municipalities and university departments. We are grateful to the participants. We acknowledge KK-stiftelsen, the insurance company Länsförsäkringar, and Emily Jamison Gromark for revision of the English.

\section{REFERENCES}

[1] Grimby A, Svanborg A. Morbidity and health-related quality of life among ambulant elderly citizen. Aging Clin Exp Res 1997; 9: 35664.

[2] McGrail K, Green B, Barer ML, Evans RG, Hertzman C, Normand C. Age, costs of acute and long-term care and proximity to death: evidence for 1987-88 and 1994-95 in British Columbia. Age Ageing 2000; $29: 249-53$.

[3] Long JM, Marshall SB. The relationship of impending death and age category to treatment intensity in the elderly. J Eval Clin Pract 2000; 6: 63-70.

[4] Levinsky NG, Yu W, Ash A, et al. Influence of age on Medicare expenditures and medical care in the last year of life. JAMA 2001; 286: 1349-55.

[5] Lagergren M. The systems of care for frail elderly persons: the case of Sweden. Aging Clin Exp Res 2002; 14: 252-7.

[6] Hellström Y, Andersson M, Hallberg IR. Quality of life among older people in Sweden receiving care from informal and/or formal helpers at home or in special accommodation. Health Soc Care Community 2004; 12: 504-16.

[7] Walter-Ginzburg A, Guralnik J, Blumstein T, Gindin J, Modan B. Assistance with personal care activities among the old-old in Israel: a national epidemiological study. J Am Geriatr Soc 2001; 49: 117684.

[8] Swedish National Board of Health and Welfare. Äldre: vård och omsorg år 2004, Kommunala insatser enligt socialtjänstlagen samt hälso- och sjukvårdslagen (Older people: care and service year 2004, municipal care and service according to Social Services Act and Health and Medical Services Act). Stockholm: National Board of Health and Welfare: 2005 (in Swedish).

[9] Shea D, Davey A, Femia EE, et al. Exploring assistance in Sweden and the United States. Gerontologist 2001; 43(5): 712-21.

[10] Hellström Y, Hallberg IR. Perspectives of elderly people receiving home help on health, care and quality of life. Health Soc Care Commun 2001; 9: 61-71.

[11] Sundström G, Johansson L, Hassing LB. The shifting balance of long term care in Sweden. Gerontologist 2002; 42(3): 350-5.

[12] Swedish Association of Local Authorities in cooperation with the federation of Swedish County Councils. Care of the Elderly in Sweden Today. Stockholm: Swedish Association of Local Authori- ties in cooperation with the federation of Swedish County Councils: 2006.

[13] SFS. The Swedish Social and Services Act (Socialtjänstlagen) Stockholm: Socialdepartementet, 2001:453.

[14] SFS. The Swedish Health and Medical Services Act (Hälso- och Sjukvårdslagen). Stockholm: Socialdepartementet, 1982:763.

[15] Ministry of Health and Social Affairs. Policy for the elderly. Fact sheet no. 14. Stockholm: Government Offices: 2005 (Accessed 1 June 2006).

[16] Jakobsson U, Hallberg IR. Mortality among elderly receiving long term care: A longitudinal cohort study. Aging Clin Exp Res 2006; 18(6): 503-11.

[17] Katz S, Ford AB, Moskowitz RW, Jackson BA, Jaffe MW. Studies of illness in the aged. The index of ADL: A standardised measure of biological and psychosocial function. JAMA 1963; 185: 914-19.

[18] Asberg KH, Sonn U. The cumulative structure of personal and instrumental ADL: A study of elderly people in a health service district. Scand J Rehabil Med 1989; 21: 171-7.

[19] Berger EY. A system of rating the severity of senility. J Am Geriatr Soc 1980; 28: 234-6.

[20] Condelius A, Edberg AK, Jakobsson U, Hallberg IR. Hospital admissions among people $65+$ related to multimorbidity, municipal and outpatient care, Arch Gerontol Geriatr 2008; 46(1): 41-55.

[21] Kristensson J, Hallberg IR, Jakobsson U. Healthcare consumption in men and women aged 65 and above in the two years preceding decision about long-term municipal care. Health Soc Care Community 2007 ; $12(6): 474-85$.

[22] Karlsson S, Edberg AK, Westergren A, Hallberg IR. Functional ability and health complaints among older people with municipa and informal care vs municipal care only. Scand J Caring Sci 2007 (accepted for publication).

[23] Polit DF, Beck CT. Nursing research: principles and methods. Philadelphia: JP Lippincott Williams \& Wilkins, 2004.

[24] Hallberg IR, Karlsson S, Westergren A, et al. Kommunal och regional vård till äldre: Vård och omsorg $\mathrm{i}$ Eslöv, Hässleholm, Malmö, Osby och Ystad till personer 65 och däröver, våren 2001 (Municipal care and care from county council for older people: Care and services in Eslöv, Hässleholm, Malmö, Osby and Ystad for persons 65 years and above, spring 2001). En delstudie i SNAC. Rapport 1. Lund: Media-Tryck, Lunds universitet, 2002 (in Swedish).

[25] Swedish National Board of Health and Welfare. Äldre: vård och omsorg år 2001 (Older people: care and service year 2001). Stockholm: National Board of Health and Welfare: 2002 (in Swedish).

[26] Kazdin AE. Research design in clinical psychology, 3rd Ed. Boston: Allyn \& Bacon; 1998.

[27] Swedish National Board of Health and Welfare. Äldre: vård och omsorg år 2005 (Older people: care and service year 2005). Stockholm: National Board of Health and Welfare: 2006 (in Swedish).

[28] Intrator O, Castle NG, Mor V. Facility characteristics associated with hospitalization of nursing home residents: results of a national study. Med Care 1999; 3: 228-37. 